\title{
Effect of Correction of the Contractured Flexed Osteoarthritic Knee on the Sagittal Alignment by Total Replacement
}

\author{
Sang-Min Lee ${ }^{1}$, Min Geun Yoon ${ }^{1}$, Myung-Sang Moon ${ }^{1}$, Bong-Jin Lee ${ }^{2}$, Sung-Rak Lee ${ }^{1}$, Young Hoon Seo ${ }^{1}$ \\ ${ }^{I}$ Department of Orthopedic Surgery, Cheju Halla General Hospital, Jeju, Korea \\ ${ }^{2}$ Department of Orthopedic Surgery, Dong-In General Hospital, Gangneung, Korea
}

Study Design: A prospective analysis of an adaptive change of the spinopelvic alignment after total knee arthroplasty.

Purpose: To evaluate the effect of correction of the contractured knee in flexion on the spinopelvic alignment by total knee arthroplasty.

Overview of Literature: Flexion contracture of the knee joint may affect the body posture and precipitate the symptoms in the lumbar spine, which is known as the 'knee-spine syndrome'.

Methods: Fifteen patients who could be followed at least over 12 months were used in this study. Neutral whole spine lateral standing radiograms taken at certain intervals were analyzed. The subjects were divided into two groups (group $A$, the patients who obtained over $10^{\circ}$ correction; group $B$, the others). The sacral slope, the pelvic tilt and the pelvic incidence were measured preoperatively and at 12 months and thereafter postoperatively in all the patients. Also, the thoracic kyphosis, lumbar lordosis, and lumbosacral angle were measured, including the spinal sagittal balance, $\mathrm{S}_{1}$ overhang and spino-sacral angle.

Results: The average correction of the contractured knee in flexion were $13.8^{\circ}$ in group $A$ and $2.7^{\circ}$ in group $B$. The median of changes of the sacral slope were $4.2^{\circ}$ in group $A$ and $-0.4^{\circ}$ in group $B$. These results revealed that there was a significant increase of the sacral slope for group $\mathrm{A}(p=0.001)$. However, there were no significant differences between the other parameters.

Conclusions: The sacral slope appears to be affected by the change of the flexion contracture after total knee arthroplasty.

Keywords: Sagittal; Alignment; Spine; Pelvis; Total knee arthroplasty

\section{Introduction}

Since the introduction of the pelvic incidence (PI), studies on the sagittal spine alignment and pelvic orientation have been increasing [1,2]. Many studies have been carried out on the sagittal alignment of the spine and pelvis during growth in the normal pediatric population, the effects of pelvic morphology on standing balance in the normal adult and in patients with certain spinal disorders including lumbar disc herniation, isthmic spondylolisthesis, lumbar degenerative disease, and adolescent and adult idiopathic scoliosis [3-11].

All the joints in the body have been structured functionally to minimize energy consumption based on the gravity line as the center during standing. A study previously found that abnormality in the hip joint caused

Received Jun 21, 2012; Revised Aug 3, 2012; Accepted Aug 4, 2012

Corresponding author: Myung-Sang Moon

Department of Orthopedic Surgery, Cheju Halla General Hospital, 65 Doryeong-ro, Jeju 690-766, Korea

Tel: +82-064-740-5410, Fax: +82-064-743-3110, E-mail: msmoonos@hotmail.com

*This study was presented in part at the 55th Annual Meeting of the Korean Orhopaedic Association on October 13th, 2011 in Seoul, Korea. 
change in spinal curvature, and induced lumbago or lower leg pain [12]. Other study have developed approach of resolving or improving lower lumbar pain after total hip arthroplasty (THA) in patients with hip and spine arthritis [13]. The knee joint and spine as well as the relationship between the hip joint and spine have been studied by Matsuyama et al. [14] and Murata et al. [15]. Murata et al. [15] reported that lumbar lordosis was significantly reduced in patients whose limitation of extension of the knee was over $5^{\circ}$ and symptoms arising from the lumbar spine might be caused indirectly by gonarthrosis, and they described this phenomenon as the "knee-spine syndrome. Based on this information, the current study was designed to analyze effect of correcting for the flexion knee contracture on the pelvic and spinal alignment after total knee arthroplasty (TKA).

\section{Materials and Methods}

\section{Material subjects}

A prospective study was carried out on fifteen patients with osteoarthritic knees who had a TKA between October 2009 and April 2010. All subjects were females. The inclusion criteria were patients with whole spine lateral radiograph in neutral standing preoperatively and at one year and postoperatively. The exclusion criteria were patients who had spinal surgery before or after TKA, postural stooping during walking, and a morphological change of the vertebral body due to traumatic or osteoporotic compression fractures and so on.

Based on the report by Murata et al. [15], we initially measured the angle of the knee joint at a $5^{\circ}$ interval. However, $5^{\circ}$ was found to be too small and did not produce any measurable changes in the proximal mobile joint alignment. Therefore, we changed the baseline measurement point from $5^{\circ}$ to $10^{\circ}$, and classified the patients
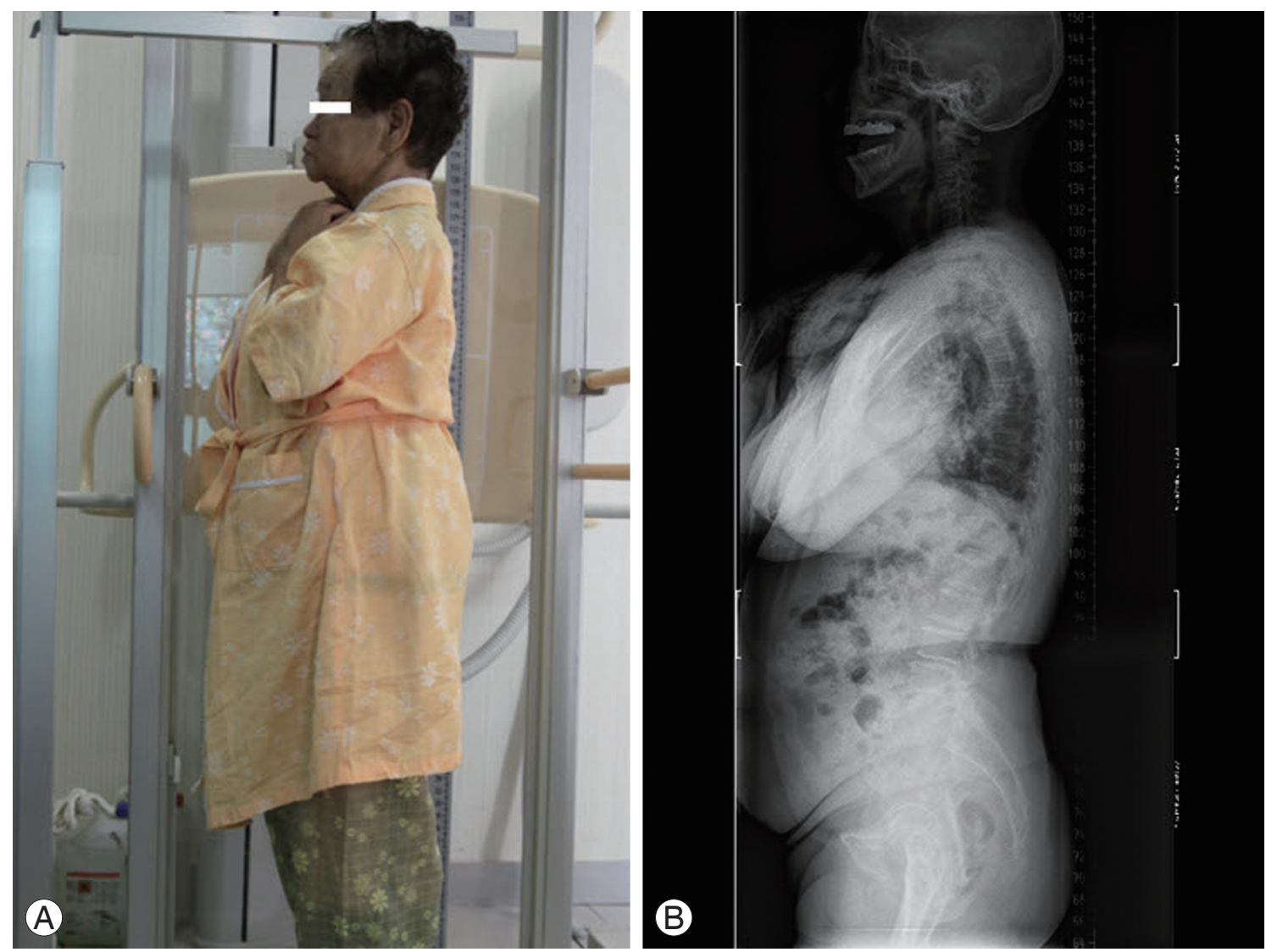

Fig. 1. A gross image (A) and standing lateral radiography (B) of the whole spine when the fist on the clavicle position, which was applied in this study. 
into two: groups A and B based on values over and less than $10^{\circ}$ instead of $5^{\circ}$ to minimize and/or to avoid measurement errors of the proximal mobile segments. The 8 patients who obtained a correction over $10^{\circ}$ were placed in group $\mathrm{A}$, and the other 7 with correction less than $10^{\circ}$ were placed in group B. This study was approved by the Institutional Review Board of the author's institute.

\section{Radiographic measurements}

The standing lateral radiographs of the whole spine with the fist on the clavicle position were taken preoperatively and at 12 months and thereafter postoperatively in all subjects. The neutral standing position was taken with the knee maximally extended and their tallest posture of hip joints and all the spine. The fist on the clavicle position was the posture where patient put one of their fingers on each side of the clavicle (Fig. 1) [16,17]. The distance between the film $(30 \times 30 \mathrm{~cm}$ size $)$ and the Roentgen beam source was $200 \mathrm{~cm}$. A whole spine radiograph was composed of three films to maintain the same level of center of the film and radiographic source. Three films were taken at a constant distance from the skull base to the femoral shaft in a regular sequence.

Digital analysis of all the radiographic measurement was done using StarPACS (Infinitt, $\pi$ View STAR, 5.0.8.1, 2003, Infinitt Healthcare, Seoul, Korea). Parameters of the spine, including the thoracic kyphosis (TK), the lumbar lordosis (LL), and the lumbosacral angle (LSA), were measured using the Cobb's angle method.

Various radiological parameters including pelvic, spinopelvic, spinal alignment and knee joint angle were measured at a one month interval by two orthopaedic surgeons to evaluate the interobserver and intraobserver

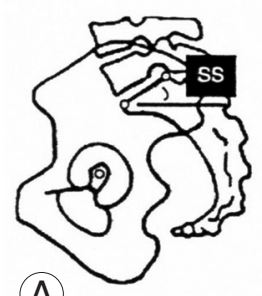
(A)

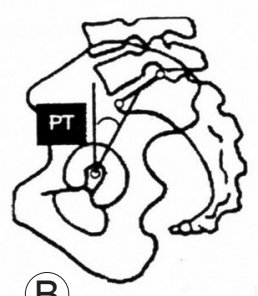

(B)

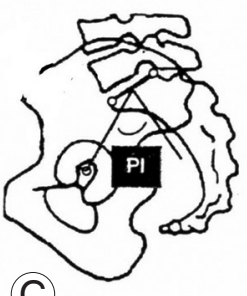

(C)
Fig. 2. Various pelvic and hip parameters. Pelvic incidence (PI) (A) is the sum of the pelvic tilt (PT) (B) and the sacral slope (SS) (C) and is fixed after maturity in a normal person. reliability. The average of four results at each parameter was used for statistical analysis.

\section{Pelvic parameters}

Pelvic parameters included in this study were the sacral slope (SS), the pelvic tilt (PT) and the PI. The SS corresponds to the angle between the sacral plate and the horizontal plane, and is changed according to the pelvis position. The PT corresponds to the angle between the line connecting the midpoint of the sacral plate to the hip axis (bi-coxo-femoral axis: midpoint between two femoral head center) and the vertical plane. PI was defined as the

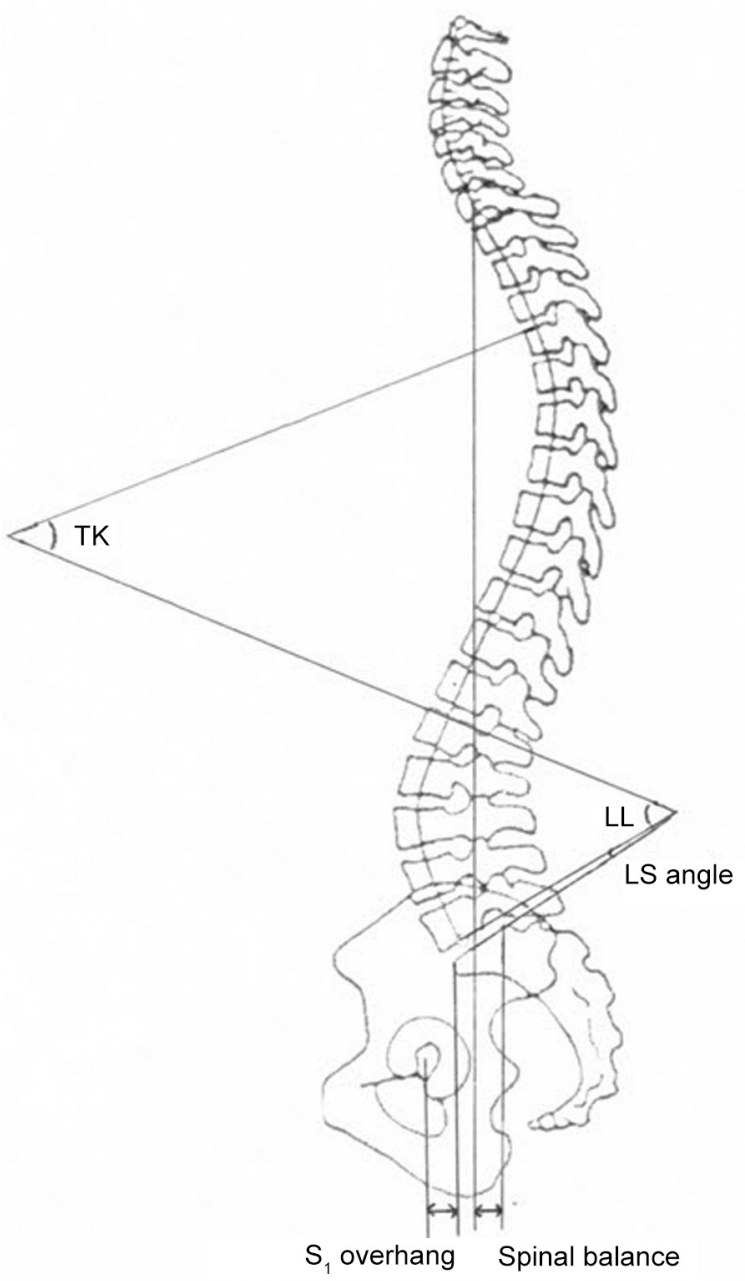

Fig. 3. The methods used to measure the thoracic kyphosis (TK) angle, lumbar lordosis (LL) angle and lumbosacral angle (LSA) are illustrated. The $S_{1}$ overhang is the shortest distance between vertical line from anterior edge of $S_{1}$ and femoral head center. The spinal balance is the shortest distance between the posterior edge of $S_{1}$ and the $C_{7}$ pulmb line. 
Table 1. The median of changes of the sacral slope, the pelvic tilt and the pelvic incidence after total knee arthroplasty at group $A$ and group $B$

\begin{tabular}{|c|c|c|c|}
\hline Pelvic parameter & $\begin{array}{c}\text { Group } A(n=8) \\
\text { (change of knee angle } \geq 10^{\circ} \text { ) }\end{array}$ & $\begin{array}{c}\text { Group } B(n=7) \\
\text { (change of knee angle }<10^{\circ} \text { ) }\end{array}$ & $p$-value ${ }^{\text {a) }}$ \\
\hline Sacral slope $\left({ }^{\circ}\right)$ & $4.2(1-8.9)$ & $-0.4(-4.3-0.1)$ & 0.001 \\
\hline Pelvic tilt $\left({ }^{\circ}\right)$ & $-1.2(-9.3-0.2)$ & $1.1(-2.4-4.6)$ & 0.073 \\
\hline Pelvic incidence $\left({ }^{\circ}\right)$ & $1.6(-1.5-5.1)$ & $0.2(-0.3-2.2)$ & 0.117 \\
\hline
\end{tabular}

Values are presented as median (range).

${ }^{\text {a) }}$ Statistical significance test was done by Mann-Whitney U-test.

angle between the perpendicular to the sacral plate and the line connecting the midpoint of the sacral plate to the hip axis. This was calculated as sum of SS and PT (Fig. 2).

\section{Spinal parameters}

On the same lateral whole spine radiograph, three spinal parameters were measured. The spinal parameters included were the LSA, LL, and TK. LSA is the angle between the sacral plate and lower endplate of $\mathrm{L}_{5}$. LL is the angle between the upper endplate of $L_{1}$ and the lower endplate of $\mathrm{L}_{5}$. TK is the angle between the upper endplate of $\mathrm{T}_{4}$ and the upper endplate of $\mathrm{L}_{1}$. These values were measured using the Cobb's angle method (Fig. 3).

\section{Spinopelvic alignment parameters}

On the same lateral whole spine radiograph, three spinopelvic alignment parameters were measured. The parameters included were the sagittal balance (SB), $\mathrm{S}_{1}$ overhang $\left(\mathrm{S}_{1} \mathrm{O}\right)$ and spino-sacral angle (SSA). SB was measured as the shortest distance between the $\mathrm{C}_{7}$ plump line and vertical line at the most posterior point of the sacral plate. $\mathrm{S}_{1} \mathrm{O}$ was measured as the shortest distance between the vertical line at the hip axis and at the most anterior point of the sacral plate. SSA was defined as the angle between the sacral plate and the line connecting the center of the $\mathrm{C}_{7}$ vertebral body and the midpoint of the sacral plate. SB and SSA were analyzed to evaluate the global SB of the spine above the pelvis (Fig. 3).

\section{Angle of the knee joint}

The flexion contracture of the knee joint was measured as an angle using a protractor, which is formed by the femoral and the tibial shafts with the lateral femoral epicondyle as the center.

\section{Statistical analysis}

All data were analyzed using IBM SPSS Statics ver. 19 (IBM, Armonk, NY, USA). Values were expressed as median and range. Differences between two groups were examined for statistical significance using the MannWhitney U-test. Changes in the PI after TKR for all fifteen patients were analyzed using the Wilcoxon Signed Rank Test. An intraclass correlation coefficients (ICCs) was calculated to assess the intraobserver and interobserver reliability. $p$-values less than 0.05 were considered statistically significant.

\section{Results}

The 8 subjects in group A had an average correction of the flexion contracture of $13.8^{\circ}$ (range, $10^{\circ}-20^{\circ}$ ) after TKR, while the 7 subjects in group $B$ had an average correction of $2.7^{\circ}$ (range, $0^{\circ}-9^{\circ}$ ). For one subject in each group, the PT and the $\mathrm{S}_{1}$ overhang $\left(\mathrm{S}_{1} \mathrm{O}\right)$ could not be measured because the femoral head center was invisible.

\section{Pelvic parameters}

The changes of the SS were $4.2^{\circ}$ (range, $1^{\circ}-8.9^{\circ}$ ) in group A and $-0.4^{\circ}$ (range, $-4.3^{\circ}-0.1^{\circ}$ ) in group $B$.

There was a significant increase of the SS in group A when compared with group B ( $p=0.001)$. However, there were no significant changes in the other pelvic parameters between the two groups.

The change in the PT was $-1.2^{\circ}$ (range, $-9.3^{\circ}-0.2^{\circ}$ ) in group $\mathrm{A}$ and $1.1^{\circ}$ (range, $-2.4^{\circ}-4.6^{\circ}$ ) in group $\mathrm{B}$, and the changes in the PI were $1.6^{\circ}$ (range, $-1.5^{\circ}-5.1^{\circ}$ ) in group $\mathrm{A}$ and $0.2^{\circ}$ (range, $-0.3^{\circ}-2.2^{\circ}$ ) in group B (Table 1). The PI did not change after TKR in these patients, which indicated that the sacroiliac joints was stable $(p=0.117)$. 
Table 2. The median of changes of the lumbar lordosis, the thoracic kyphosis and the lumbosacral angle after total knee arthroplasty at group $A$ and group B

\begin{tabular}{lccc}
\multicolumn{1}{c}{ Spinal parameter } & $\begin{array}{c}\text { Group A }(\mathrm{n}=8) \\
\left.\text { (change of knee angle } \geq 10^{\circ}\right)\end{array}$ & $\begin{array}{c}\text { Group B }(\mathrm{n}=7) \\
\left(\text { change of knee angle }<10^{\circ}\right)\end{array}$ & $\begin{array}{c}p \text {-value } \\
\text { Lumbosacral angle }\left(^{\circ}\right)\end{array}$ \\
\hline Lumbar lordosis $\left(^{\circ}\right)$ & $0.9(-2-3.8)$ & $0.5(-3-2.3)$ & 0.336 \\
\hline Thoracic kyphosis $\left({ }^{\circ}\right)$ & $1.9(-2.8-3.5)$ & $-0.2(-5.1-2.8)$ & 0.867 \\
\hline
\end{tabular}

Values are presented as median (range).

${ }^{\text {a) }}$ Statistical significance test was done by Mann-Whitney U-test.

Table 3. The median of changes of the spinal balance, the $S_{1}$ overhang and the spino-sacral angle after total knee arthroplasty at group $A$ and group $B$

\begin{tabular}{lccc}
$\begin{array}{c}\text { Spinopelvic alignment } \\
\text { parameter }\end{array}$ & $\begin{array}{c}\text { Group A }(\mathrm{n}=8) \\
\left.\text { (change of knee angle } \geq 10^{\circ}\right)\end{array}$ & $\begin{array}{c}\text { Group B (n=7) } \\
\left(\text { change of knee angle }<10^{\circ}\right)\end{array}$ & $\begin{array}{c}p \text {-value }{ }^{\text {a) }} \\
\text { Sagittal balance }(\mathrm{mm})\end{array}$ \\
\hline S overhang $(\mathrm{mm})$ & $24(-52-40)$ & $2(-34-21)$ & 0.281 \\
Spino-sacral angle $\left(^{\circ}\right)$ & $-2(-12-2)$ & $2(-2-12)$ & 0.730 \\
\hline
\end{tabular}

Values are presented as median (range).

${ }^{\text {a) }}$ Statistical significance test was done by Mann-Whitney U-test.

\section{Spinal parameters}

The changes of the lumbar lordosis, the TK and the LSA were $1.9^{\circ}$ (range, $\left.-2.8^{\circ}-3.5^{\circ}\right),-1.7^{\circ}\left(\right.$ range, $-9.2^{\circ}-8^{\circ}$ ), and $0.9^{\circ}$ (range, $-2^{\circ}-3.8^{\circ}$ ) in group $\mathrm{A}$ and $-0.2^{\circ}$ (range, $\left.-5.1^{\circ}-2.8^{\circ}\right),-0.9^{\circ}\left(\right.$ range, $\left.-6.1^{\circ}-6.7^{\circ}\right)$, and $0.5^{\circ}$ (range, $-3^{\circ}-2.3^{\circ}$ ) in group B. There was no significant difference in the change of all the spinal parameters including LL $(p=0.867)$, TK $(p=0.397)$ and LSA $(p=0.336)$ after TKR (Table 2).

\section{Spinopelvic alignment parameters}

The changes of the SB were $24 \mathrm{~mm}$ (range, $-52-40 \mathrm{~mm}$ ) in group $A$ and $2 \mathrm{~mm}$ (range, $-34-21 \mathrm{~mm}$ ) in group $B$. The SB in six out of the eight group A patients changed positively, while the $S B$ of the remaining two patients changed negatively. The SB in five out of the seven group $\mathrm{B}$ patients changed positively and the remaining two patients changed negatively. There were no constant directional change and significant difference in SB between the two groups after TKR $(p=0.281)$.

The change of the $S_{1}$ overhang was $-2 \mathrm{~mm}$ (range, $-12-2 \mathrm{~mm}$ ) in group A and $2 \mathrm{~mm}$ (range, $-2-12 \mathrm{~mm}$ ) in group B. The change in the SSA was $-2.5^{\circ}$ (range, $-9.4^{\circ}-1^{\circ}$ ) in group $\mathrm{A}$ and $-1^{\circ}$ (range, $-4.2^{\circ}-3.4^{\circ}$ ) in group B. However, there were no significant difference in the change of the $S_{1}$ overhang $(p=0.73)$ and SSA $(p=0.189)$ between the two groups after TKR (Table 3).

\section{Intraobserver and interobserver reliability}

Intraobserver and Interobserver reliability were calculated with an ICCs. ICCs calculated in this study varied between 0.821 and 0.978 . ICCs of the lumbar lordosis, the TK and LSA were $0.856,0.821$ and 0.911 , respectively. ICCs of the SS and the PT were 0.968 and 0.978 , respectively. ICCs of the SB and $\mathrm{S}_{1}$ overhang were 0.978 and 0.928 , respectively.

\section{Discussion}

Sagittal spinal alignment helps distribute one's body weight through the pelvic girdle to minimize energy consumption when standing. Some authors have reported that the development of this spinal curvature was influenced by the pelvic incidence, and that spinal balance was determined by lumbosacral and pelvic alignment, including hip joint in the aging process $[4,18]$. Some authors have also reported relationships between individual spinal SB and sagittal pelvic malrotation, which influences acetabular cup orientation [19]. As well the relationships between spinal curvature and pelvic morphology, the relationships between hip joint and spine, and knee joint and spine have been studied. Parvizi et al. [13] reported that the pain experienced by patients presenting hip ar- 
thritic and lower lumbar pain could often be resolved or improved after THA. Jackson and McManus [20] found that the LL and the sacral inclination were related to the degree of extension of the hip. An abnormality in the hip joint has been shown to cause an abnormal curvature of the sagittal alignment of the spine and induce lumbago. This phenomenon has been referred to as the 'hip-spine syndrome' by Offierski and MacNab [12,21]. Murata et al. [15] also studied the relationship between knee joint and spine, and reported that symptoms arising from the lumbar spine might be caused by degenerative changes in the knee and this has been referred to as the 'knee-spine syndrome'.

In the current study, all the spinal parameters including the lumbosacral angle, the lumbar lordosis, and TK did not change significantly after TKA even in group A, in which a correction of over $10^{\circ}$ was obtained. It was assumed that the results were caused by fixing the spinal curvature of the degenerated spinal column, including the intervertebral disc. The short follow-up period was also assumed to be another reason.

Murata et al. [15] reported that knee angle did not correlate with the sacral inclination. However, in the current study there was a significant increase in the SS of group A when compared with group B (Figs. 4, 5). This result indicates that the change of the knee joint angle had a greater affect on the nearest and most mobile segments, such as the hip and pelvis than the fixed degenerative spine.

The SS was influenced more by a change in the standing posture. So it seemed that correction of the flexion
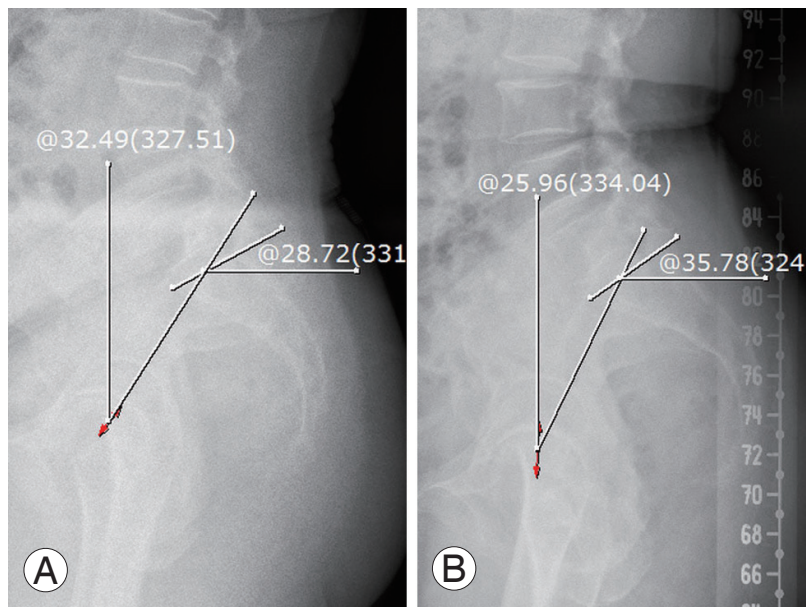

Fig. 4. The sacral slope and the pelvic tilt at preoperative (A) and 1 year postoperative $(\mathbf{B})$ radiographies of the same patient, who had obtained over ten degrees of correction of the knee flexion contracture after total knee arthroplasty. contracture of the knee joint induced an extension of the hip joint to place the gravity line along the hip axis by balance of the hamstring, quadriceps, torso and pelvic muscles [21-23].

Consequently, this extension of the hip joint could induce an increase in the SS.

It has been reported that the PI tends to increase from 4 to 18 years of age, which is caused by an increase in the PT to place the center of gravity over the hips and lower limbs. Each individual has his or her constant PI after growth except when sacroiliac dissociation occurs.

The PI can be calculated by the summation of two parameters (SS and PT). So in adults, the increase of the SS induces a decrease in the PT [3]. According to this hypothesis, the PT should have decreased significantly in the current study in group A, but this was not observed. We assumed that these results were not caused by errors in measuring the angle of the spine, pelvis and spinopelvic sagittal alignment, but by the error in taking correct lateral radiographs.

All the angles were measured twice by two observers and the results between the intraobserver and interobserver were highly reliable. But there was a different pelvic rotation in each occasion in the lateral standing whole spine radiography. In many cases, a different location of the two femoral heads was observed in the radiographs. The distance between centers of the two femoral heads was different for each radiograph. It is essential to completely overlap the femoral head. As the pelvis rotated, the midpoint of the upper endplate of the sacrum changed.
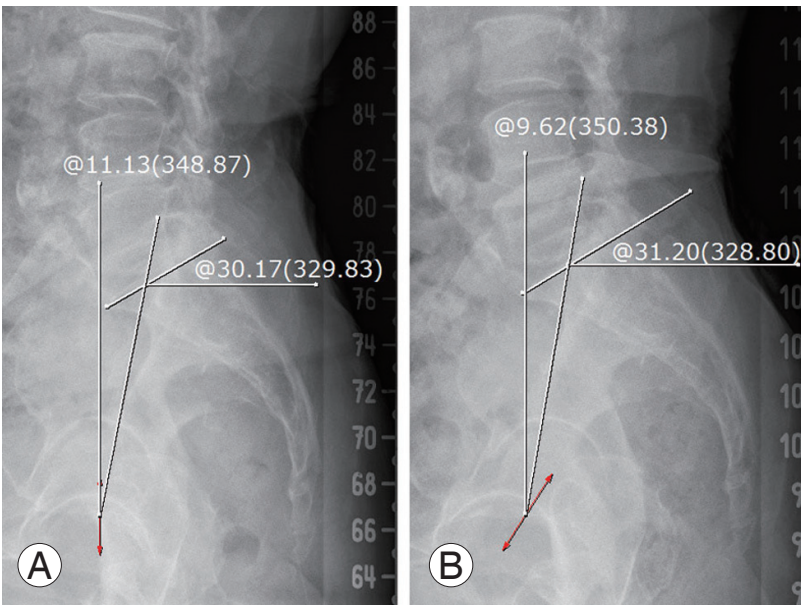

Fig. 5. The sacral slope and the pelvic tilt in preoperative $(\mathbf{A})$ and 1 year postoperative $(\mathbf{B})$ radiographies of the same patient, who had obtained less than ten degrees correction of the knee flexion contracture after total knee arthroplasty. 
So the PT could be changed (Fig. 6).

But even though there was no significant difference between group A and group B in the change of the PT ( $p=0.073$ ), the opposite directional changes of the SS and the PT were noted in 11 out of 13 patients.

In the current study, there were no meaningful changes in the PI after TKR. The reason for this result was that the pelvis moved as a single unit unless there was dissociation between the ilium and the sacrum. That is, the PI did not change in the adult if there was no sacroiliac dissociation. Thus, in the current study the measured minimal postoperative change in PI was thought to be due to an error in measurement between the two groups. The sacroiliac joint become stiff after the age of fifty years or more and as a consequence the pelvis tilts as a unit.

Jackson and McManus [20] reported that the vertical sagittal axis (VSA) was located within $2.5 \mathrm{~cm}$ centering as the most posterior superior corner of $S_{1}$, and was moved anteriorly with gradual stooping during the aging process. Kim et al. [18] reported that there was about $15.4 \mathrm{~mm}$ of meaningful anterior movement of VSA between the ages of 55 and 66 in comparison with that between the ages of 20 and 30. The increase of the PT and the decrease in the SS induce anterior movement of the $\mathrm{C}_{7}$ vertebral body. In the current study, we anticipated posterior movement of the $\mathrm{C}_{7}$ vertebral body and a change of the SB into the negative direction. But there was no significant difference in the SB between two groups.

There are several possible reasons for these results; First, even though standardization of the subject posture was applied using the fist on the clavicle position, each
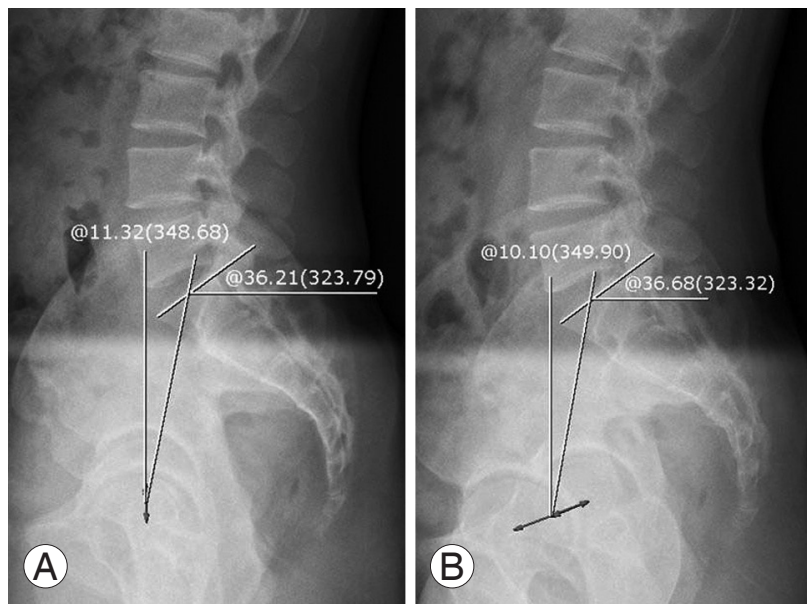

Fig. 6. The radiographs, taken in different position [true lateral position (A) and slight oblique position (B)] of the same person at the same time. Pelvic tilt could be changed by rotation of the pelvis. individual posture was not constant. Slight forward bending of one's body changes the SB into the positive direction. On the contrary, a slight backward tilt changes that SB into the negative direction (Fig. 7). Particularly, some subjects preoperatively could hardly stand in a standardized posture due to pain in the the knee joint. The second reason was that the fixed curvature of the aged spine could not be compensated against the change in the flexed knee. Kim et al. [18] reported that there was a limitation in the SB when evaluating the spinal balance due to the large standard deviation. In the current study, there was also a large standard deviation in the SB for each subject. So it is believed that the pelvic parameters are more useful factor to evaluate the spine than the SB and the SSA. There were some limitations to this study. First was the small number of material subjects, and the short follow-up period, which was 15 months. The second limitation was that the relationship between the clinical symptoms including lumbago and changes of the sagittal alignment parameters could not be estimated.

\section{Conclusions}

There was a meaningful increase of the SS in the patients who obtained a correction in the knee extension range of over $10^{\circ}$. Therefore, the assumptive conclusion is that a change in the flexion contracture after TKA had an effect on the SS.

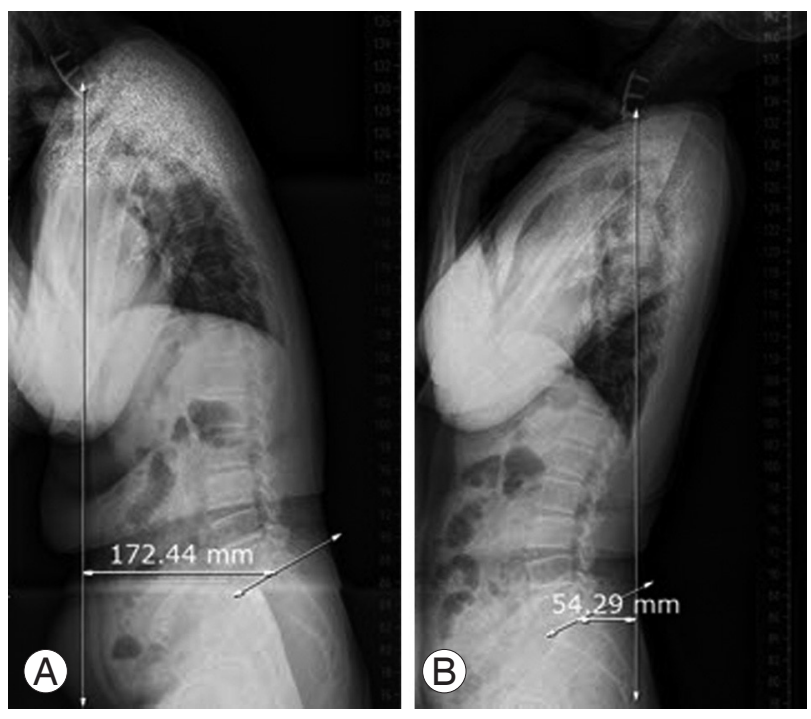

Fig. 7. Variance of the spinal sagittal balance as a function of the positional change [flexion ( $\mathbf{A}$ ) and extension (B)] for the same person, at the same time. 


\section{Conflict of Interest}

No potential conflict of interest relevant to this article was reported.

\section{References}

1. Duval-Beaupere G, Robain G. Visualization on full spine radiographs of the anatomical connections of the centres of the segmental body mass supported by each vertebra and measured in vivo. Int Orthop 1987;11:261-9.

2. Legaye J, Duval-Beaupere G, Hecquet J, Marty C. Pelvic incidence: a fundamental pelvic parameter for three-dimensional regulation of spinal sagittal curves. Eur Spine J 1998;7:99-103.

3. Mac-Thiong JM, Berthonnaud E, Dimar JR 2nd, Betz RR, Labelle H. Sagittal alignment of the spine and pelvis during growth. Spine (Phila Pa 1976) 2004;29:1642-7.

4. Lee CS, Chung SS, Chung KH, Kim SR. Significance of pelvic incidence in the development of abnormal sagittal alignment. J Korean Orthop Assoc 2006;41:274-80.

5. Jackson RP, Hales C. Congruent spinopelvic alignment on standing lateral radiographs of adult volunteers. Spine (Phila Pa 1976) 2000;25:2808-15.

6. Jackson RP, Kanemura T, Kawakami N, Hales C. Lumbopelvic lordosis and pelvic balance on repeated standing lateral radiographs of adult volunteers and untreated patients with constant low back pain. Spine (Phila Pa 1976) 2000;25:575-86.

7. Endo K, Suzuki H, Tanaka H, Kang Y, Yamamoto K. Sagittal spinal alignment in patients with lumbar disc herniation. Eur Spine J 2010;19:435-8.

8. Labelle H, Roussouly P, Berthonnaud E, Dimnet J, O'Brien M. The importance of spino-pelvic balance in L5-s1 developmental spondylolisthesis: a review of pertinent radiologic measurements. Spine (Phila $\mathrm{Pa}$ 1976) 2005;30:S27-34.

9. Barrey C, Jund J, Noseda O, Roussouly P. Sagittal balance of the pelvis-spine complex and lumbar degenerative diseases: a comparative study about 85 cases. Eur Spine J 2007;16:1459-67.

10. Tanguay F, Mac-Thiong JM, de Guise JA, Labelle H. Relation between the sagittal pelvic and lumbar spine geometries following surgical correction of adolescent idiopathic scoliosis. Eur Spine J 2007;16:531-6.
11. Li WS, Li G, Chen ZQ, Wood KB. Sagittal plane analysis of the spine and pelvis in adult idiopathic scoliosis. Chin Med J (Engl) 2010;123:2978-82.

12. Offierski CM, MacNab I. Hip-spine syndrome. Spine (Phila Pa 1976) 1983;8:316-21.

13. Parvizi J, Pour AE, Hillibrand A, Goldberg G, Sharkey PF, Rothman RH. Back pain and total hip arthroplasty: a prospective natural history study. Clin Orthop Relat Res 2010;468:1325-30.

14. Matsuyama Y, Hasegawa Y, Yoshihara H, et al. Hipspine syndrome: total sagittal alignment of the spine and clinical symptoms in patients with bilateral congenital hip dislocation. Spine (Phila Pa 1976) 2004;29:2432-7.

15. Murata Y, Takahashi K, Yamagata M, Hanaoka E, Moriya $\mathrm{H}$. The knee-spine syndrome. Association between lumbar lordosis and extension of the knee. J Bone Joint Surg Br 2003;85:95-9.

16. Faro FD, Marks MC, Pawelek J, Newton PO. Evaluation of a functional position for lateral radiograph acquisition in adolescent idiopathic scoliosis. Spine (Phila Pa 1976) 2004;29:2284-9.

17. Kim WJ. Optimal standing radiographic positioning in patients with sagittal imbalance. J Korean Soc Spine Surg 2010;17:198-204.

18. Kim WJ, Kang JW, Yeom JS, et al. A comparative analysis of sagittal spinal balance in 100 asymptomatic young and older aged volunteers. J Korean Soc Spine Surg 2003;10:327-34.

19. Legaye J. Influence of the sagittal balance of the spine on the anterior pelvic plane and on the acetabular orientation. Int Orthop 2009;33:1695-700.

20. Jackson RP, McManus AC. Radiographic analysis of sagittal plane alignment and balance in standing volunteers and patients with low back pain matched for age, sex, and size. A prospective controlled clinical study. Spine (Phila Pa 1976) 1994;19:1611-8.

21. Geiger EV, Muller O, Niemeyer T, Kluba T. Adjustment of pelvispinal parameters preserves the constant gravity line position. Int Orthop 2007;31:253-8.

22. Legaye J, Duval-Beaupere G. Gravitational forces and sagittal shape of the spine: clinical estimation of their relations. Int Orthop 2008;32:809-16.

23. Raschke U, Chaffin DB. Trunk and hip muscle recruitment in response to external anterior lumbosacral shear and moment loads. Clin Biomech (Bristol, Avon) 1996;11:145-52. 